Reprod. Nutr. Dévelop., 1988, 28 (1), 85-86.

\title{
Effets de l'apport d'aliment concentré à des agneaux au pâturage sur le parasitisme par les strongles gastro-intestinaux
}

Sophie PRACHE

Laboratoire de la Production Ovine,

I.N.R.A., Theix, 63122 Ceyrat, France

Summary. Supplementation of unweaned grazing lambs reduced lamb infestation and increased lamb growth rate (especially when parasitism of unsupplemented lambs was high) and also reduced pasture contamination.

Nous avons déterminé les effets de l'apport d'aliment concentré au pâturage sur le niveau d'infestation parasitaire d'agneaux non sevrés et sur le niveau de contamination des prairies.

Matériel et méthodes. Trois groupes de 24 agneaux lle-de-France nés début mars et allaités doubles, ont été élevés au pâturage de la mise à l'herbe (24 avril 1984 et 26 avril 1985) au sevrage ( 25 juin 1984 et 24 juin 1985). Ils ont chacun été répartis en 2 lots de 12 agneaux, I'un complémenté à volonté avec du maïs grain (C), l'autre non complémenté (NC). Chaque lot a pâturé ses propres parcelles à raison de trois passages en 1984 et de 2 en 1985, les dates de changement de parcelle ayant été identiques pour les lots d'une même année. Les parcelles provenaient du découpage d'une parcelle pâturée en un seul bloc l'année précédente (1984) ou qui n'avait jamais été pâturée (1985). Les agneaux n'ont pas reçu de traitement antiparasitaire. On a dénombré les larves L3 sur une des parcelles, à la mise à l'herbe et au sevrage. On a effectué des coproscopies individuelles à la mise à l'herbe sur les brebis et en cours d'essai sur les agneaux ; sur ces derniers, on a mesuré l'évolution du taux de pepsinogène sérique. La répartition des brebis et des parcelles entre les lots a été faite de manière à ce que le niveau de parasitisme initial soit plus faible pour les lots NC (tabl. 1).

TABL. 1. - Conditions expérimentales.

\begin{tabular}{|c|c|c|c|c|c|c|}
\hline \multirow{2}{*}{$\frac{\text { Année (numéro de l'essai) }}{\text { Lot }}$} & \multicolumn{2}{|c|}{1984 (1) } & \multicolumn{2}{|c|}{$1985(2)$} & \multicolumn{2}{|c|}{$1985(3)$} \\
\hline & $\mathrm{NC} 1$ & $\mathrm{C} 1$ & NC2 & $\mathrm{C} 2$ & NC3 & $\mathrm{C} 3$ \\
\hline Chargement (brebis/ha) & 11,8 & 11,6 & 13,8 & 13,8 & 21,1 & 19,5 \\
\hline Quantité d'herbe offerte (gMS/kg PV.j) & 73,7 & 72,7 & 67,2 & 67,2 & 46,3 & 45,0 \\
\hline Quantité d'herbe résiduelle (kg MS/ha) & 1314 & 1946 & & & & \\
\hline $\begin{array}{l}\text { Hauteur de l'herbe résiduelle }(\mathrm{cm}) \\
\text { A la mise à l'herbe: }\end{array}$ & & & 11,17 & 11,10 & 7,16 & 7,87 \\
\hline - Nombre moyen d'œufs émis par les brebis & 240 & 489 & 666 & 1710 & 777 & 807 \\
\hline - Nombre de larves L3/kg MS & 37 & 73 & 0 & 0 & 0 & 0 \\
\hline
\end{tabular}


Résultats et discussion. A même quantité d'herbe offerte, la quantité d'herbe résiduelle a été généralement plus élevée pour les lots complémentés (tabl. 1) ; ceux-ci auraient donc ingéré moins d'herbe. Le nombre d'œufs émis (fig. 1) a été plus faible pour les agneaux complémentés dans I'essai $1(P<0,05)$; dans

Nombre d'oeufs par grame de fèces

Essai 1

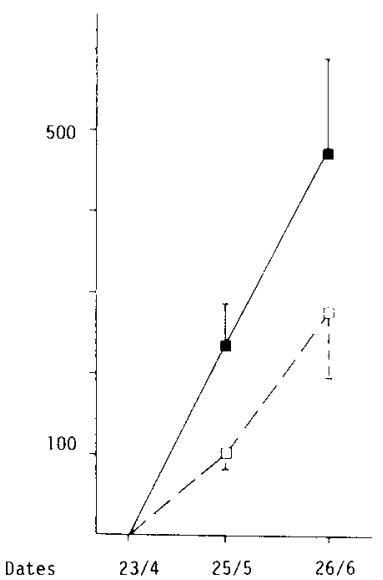

Taux de pepsinogène sérique (mU TYR)

Essài

Essais 2 (H*)

et $3(\Delta \Delta)$

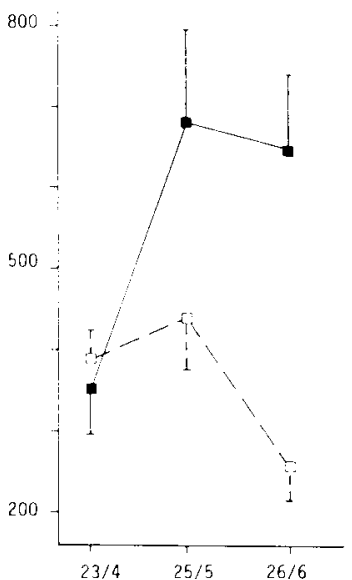

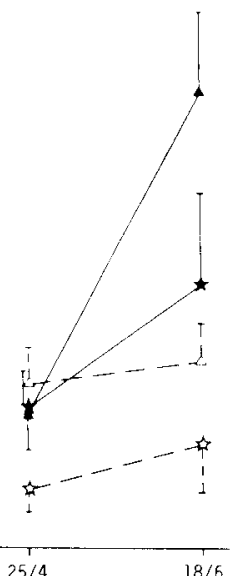

FIG. 1. - Niveau d'infestation parasitaire des agneaux complémentés (- - -) et non complémentés (-) (valeur moyenne et écart-type de la moyenne).

les essais 2 et 3, aucun œuf n'était encore émis au sevrage (période prépatente non terminée). Le taux de pepsinogène sérique (fig. 1), corrigé pour le taux avant la mise à l'herbe, a été plus faible pour les agneaux complémentés, significativement dans les essais 1 ( $P<0,001)$ et $3(P<0,05)$, non significativement dans l'essai 2 (respectivement 433, 358 et $159 \mathrm{mU}$ TYR en moins au sevrage). Le nombre de larves L3 sur le pâturage après le $3^{\circ}$ cycle était plus faible pour C1 que pour NC1 : par kg MS d'herbe, 29 vs 428 Teladorsagia, 29 vs 215 Haemonchus, 119 vs 80 Trichostrongylus, 60 vs 80 Nematodirus. II n'a pas été mesuré dans les autres essais. Les vitesses de croissance ont été améliorées par la complémentation, significativement dans l'essai 3 (226 vs $287 \mathrm{~g} / \mathrm{j}-\mathrm{P}<0,001)$, non significativement dans les essais 1 et 2 (269 vs $294 \mathrm{~g} / \mathrm{j}, 276$ vs $277 \mathrm{~g} / \mathrm{j}$ ). Les agneaux recevant un aliment concentré ingèrent moins d'éléments infestants, parce qu'ils ingèrent moins d'herbe (Newton et Young, 1974) et qu'ils pâturent moins ras (Gruner, 1979). Etant moins parasités, ils contaminent moins leur pâturage. L'effet de la complémentation a été surtout marqué lorsque le niveau d'infestation des agneaux non complémentés était élevé.

Nous remercions D. Kerbœuf (Centre de Recherches I.N.R.A.-Tours). 